Revista Iberoamericana, Vol. LXXII, Núm. 214, Enero-Marzo 2006, 155-169

\title{
MÁS ALLÁ DEL INTERIOR MODERNISTA: EL ROSTRO PORFIRIANO DE LA REVISTA MODERNA (1903-1911)
}

\author{
POR \\ Adela Pineda Franco \\ Boston University
}

La Revista Moderna (1898-1903), posteriormente Revista Moderna de México (1903-1911), ${ }^{1}$ se ha leído siguiendo criterios de periodización literaria, ya sea como receptáculo de una literatura nacional, la mexicana, en un determinado momento histórico, o en relación a la historiografía del modernismo hispanoamericano, siguiendo el criterio epocal de Max Henríquez Ureña. ${ }^{2}$ No obstante, otros marcadores relacionados con la materialidad de la revista, como formato, precio, gráfica, publicidad y géneros discursivos predominantes, deben ser considerados en relación a estos contenidos estéticos para señalar la contradicción que ella misma encarna como formación literaria, antiburguesa y decadentista, como publicación seriada de lujo en un mercado, como vehículo de comunicación social dentro de un periodismo que se pretendía empresarial y no partidista, y como instrumento ideológico del régimen de Porfirio Díaz, conocido como Porfiriato (1876-1911).

A lo largo de sus dos épocas, la $R M$ sostuvo un elitismo literario frente al público pero, a la vez, participó en la (re)producción de sujetos ciudadanos pertinentes a la cultura del orden y el progreso, a partir del incremento en la demanda lectora que la modernización de la prensa y del estado había acarreado. Para su segunda época, la revista se había convertido en un foro donde se concatenaron diversos grupos letrados, diversos discursos, saberes e intenciones: del modernismo al ateneísmo, del discurso cívico a la crónica social, de la gráfica decadentista a la fotografía cotidiana, de la literatura a la educación y a la historia. En este foro se debatieron variadas posturas frente a las transformaciones culturales, pero siempre dentro de los límites del concepto de ciudadanía porfiriana. Con la mira de ejemplificar lo anterior, partimos de la autoconcepción inicial de los fundadores de la revista en términos de su apelación a un lector modelo, para después explorar, en textos e imágenes de diversa índole provenientes de la misma revista, la creciente

\footnotetext{
${ }^{1}$ Las citas sobre la primera época provienen de la edición facsimilar (Universidad Nacional Autónoma de México, 1997). A pesar de que varios estudiosos consideran que se trata de dos revistas, aquí se usará la abreviatura $R M$ para referirse a las dos épocas indistintamente.

2 Como suma de la literatura mexicana decimonónica, consultar Héctor Valdés y Julio Torri; un análisis bajo los criterios de periodización de Max Henríquez Ureña en su Breve historia del modernismo (1954) que dividen al modernismo en dos épocas -una tendiente hacia la forma y otra hacia el espíritu- se encuentra en Holdsworth.
} 
capacidad de ésta para atraer a un público más amplio, pero conservando su carácter elegante, sosteniendo un cosmopolitismo nacionalista y sustentando una complicidad con el estado. Aquí cabe señalar que la pérdida del archivo de la $R M$ (Valdés, Índice 15), nos impide brindar datos cuantitativos sobre su recepción; carecemos de información sobre el número de sus subscriptores y el de su tiraje. Las reflexiones que este ensayo elabora al respecto provienen de fuentes secundarias y de las evidencias que proporciona la propia revista.

La estrategia de legitimación inicial de la $R M$ se fundaba en la automarginación de sus productores Balbino Dávalos, Jesús Urueta, Rubén M. Campos, Ciro B. Ceballos, Bernardo Couto Castillo, José Juan Tablada y Julio Ruelas frente al público. La caracterización de los mismos aparece en los debates que propiciaron su fundación, ${ }^{3}$ en las “Apologías” que Ceballos hizo de sus compañeros de redacción (1898-1899), ${ }^{4}$ en algunas semblanzas de la serie "Máscaras”, aparecidas en la $R M$ a partir del sexto año, y en la gráfica de Ruelas, el pintor zacatecano que distinguió a la $R M$ con 2564 ilustraciones. ${ }^{5}$ Estos textos e imágenes proponen nuevas formas de sociabilidad literaria, como las ensayadas en el bar, ${ }^{6}$ con el fin de construir un espacio cultural antagónico, en apariencia, a la moral pública encarnada en Doña Carmen Romero Rubio, la católica esposa de Don Porfirio, pero a la sombra de restricciones de género y mediante una marcada misoginia. Al reverso del hombre porfiriano, hacedor del espacio público y protector del privado, la revista exhibe las patologías del héroe decadente. El receptor idóneo para una revista que promueve el decadentismo, se formula sobre la base del campo europeo, y es el que lee a Barbey d’Aurevilly (Ceballos, “Balbino Dávalos” [1 Jul. 1898]: 11). Dentro de esta formulación, se erige una crítica a las prácticas lectoras de la burguesía porfiriana, a la vez que se expone la marginalidad del escritor finisecular frente al público.

Al lado de esta configuración del lector modelo como cofrade de los productores decadentistas, la revista proporciona evidencias de su recepción histórica al publicar cartas y reseñas provenientes de otras publicaciones: un balance de El Mercurio de América de Buenos Aires (15 Dic. 1898: 158), una polémica entablada con La Estrella Occidental (159-60), una reseña crítica de El Combate, (Ene. 1899: 32) y un artículo de El Cojo Ilustrado sobre revistas mexicanas (Oct. 1905: 77-78). En todos estos casos, se trata de una recepción literaria; El Mercurio y El Cojo ubican la producción de la RM dentro del Modernismo Hispanoamericano, La Estrella Occidental y El Combate demarcan territorios estéticos e ideológicos al interior de la ciudad letrada mexicana. No obstante, estas reseñas también aluden a otros lectores no necesariamente protagonistas de las contiendas literarias. El texto argentino cita al público mexicano que probablemente no

\footnotetext{
${ }^{3}$ Los debates se dieron entre el grupo de la $R M$ y sus detractores, Carmen Romero Rubio, esposa del presidente Díaz, y el crítico Victoriano Salado Álvarez. La primera polémica se inició en El País (1893), la segunda, en el Universal (1898). Para un resumen de éstas, consultar Schneider.

${ }^{4}$ A Dávalos (1 Jul. 1898): 9-12; a Delgado (15 Ag. 1898): 20-23; a Ruelas ( 15 Sept. 1898): 55-57; a Valenzuela (1 Nov. 1898): 102-05, y a Urueta (Feb. 1899): 40-42.

${ }^{5}$ Sin contar repeticiones, este número de ilustraciones se reduce a 431. Para un estudio temático de la obra de Ruelas en la $R M$, consultar Rodríguez Lobato.

${ }^{6}$ Sbre el bar, consultar: Ceballos (15 Sept. 1898): 55; Ugarte (15 Jun. 1900): 183 y Campos, “Cuento bohemio" (1 de Ag. 1901): 266-68, además de su libro póstumo El bar.
} 
conoce el poema de Lugones reseñado por Tablada (158). La nota de la redacción se dirige a los contrincantes del debate mexicano, José M. Facha, Manuel Caballero y Tablada, pero también a "nuestros subscriptores" (158), alusión que reaparecerá frecuentemente en la revista, resaltando la importancia de este sector. Para la segunda época, la apertura de "Revista de Revistas”, una amplia sección (dos a cuatro páginas) dedicada al comentario y difusión de otras revistas, nacionales, provincianas, internacionales y ya no exclusivamente literarias, sugiere que, para entonces, la lectura de publicaciones periódicas se había incrementado y era índice de la afluencia de lectores que no leían únicamente a Barbey d’Aurevilly y que preferían el periódico al libro.

Por otra parte, el elitismo literario articulado a través de la figura del lector modelo se sostiene a lo largo de las dos épocas de la revista, aunque no desde el deslinde decadentista, sino desde el ángulo de la alta cultura, esfera donde se mueve un público exclusivamente masculino. Un caso ejemplar se da en agosto de 1909, cuando la revista se dirige a "los hombres cultos” prediciendo la buena acogida que éstos darán a una serie de cambios sustanciales en el formato (16). Dicha demarcación entra en plena contradicción con la evidente intención editorial de diversificar e incrementar la lectura de la revista, incluyendo a un amplio sector femenino, como se verá más adelante, a través de sucesivas transformaciones materiales a partir de 1899. En este año, aparece la siguiente nota de la redacción: “Avisamos a nuestros subscriptores que desde este ejemplar ... se publicará nuestro periódico mensualmente, con treinta y dos páginas -en lugar de diez y seis- ... con dibujos intercalados en el texto y papel de la misma calidad del presente número” (32). ${ }^{7}$

Sin embargo, esta diversificación del público está limitada por factores socioeconómicos. La suscripción mensual de 50 centavos en la capital, precio alto considerando que el de un periódico medio fluctuaba entre 3 y 12 centavos (Speckman 35), da pautas para suponer que los lectores de la $R M$ conformaban, no sólo el reducido núcleo de estetas y hombres cultos, sino un sector afluente, competente, citadino, persuadido de la prosperidad del régimen y convencido de su participación en una cultura cosmopolita. A estos porfirianos se dirigen los contados anuncios publicitarios de artículos de lujo (tapices, seguros, cigarros y perfumes) que la revista publica, y no a aquellos que viven con el salario promedio de la época, precisamente de cincuenta centavos diarios. ${ }^{8} \mathrm{La} R M$ da cuenta de lo elegante, la marca de una administración que había puesto la cultura al servicio de su supuesto progreso.

Si tomamos en cuenta estas condiciones socioeconómicas, es obvio que el esfuerzo por incrementar y diversificar la lectura por parte de los productores de la revista no haya sido suficiente para hacer de ella un producto de libre circulación en un mercado. Como publicación periódica especializada, la $R M$ se ubica entre el periodismo noticioso de grandes tirajes y bajos costos, y la prensa de a centavo, amarillista, supersticiosa, satírica y ampliamente ilustrada que circula en hojas volantes. En general, el espacio de acción del

\footnotetext{
${ }^{7}$ De 1900 a 1903, la revista vuelve a ser quincenal, con una extensión de ocho a quince páginas. El papel mate, “de no muy buena calidad” según Valdés (Índice 19), se conserva hasta el cuarto año de publicación (1901), cuando se introduce papel satinado, tipo cuché (20).

${ }^{8}$ A principios de siglo, los obreros ganaban entre cincuenta centavos y un peso. El salario de las mujeres (costureras, lavanderas, sirvientas) era menor (Speckman 35).
} 
periodismo especializado fue restringido, si se toma en cuenta que la población del país no dejaba de ser altamente rural y heterogénea. El nivel de alfabetización, la presencia de comunidades lingüísticas diversas, la rudimentaria infraestructura de circulación de los periódicos, la accidentada topografía y los ingresos de la población asalariada, sugieren que el porcentaje de lectores potenciales era menor a los 2.5 millones en un país habitado por nueve. ${ }^{9}$ De aquí que su proliferación y larga supervivencia (como es el caso de la $R M$ ) siga intrigando a los investigadores dados los bajos índices de competencia cultural. (Bazant, "Lecturas" 207).

La propia revista da cuenta de estas limitaciones. En un artículo que conmemora sus diez años, los redactores señalan que no pudieron apoyarse en sus subscriptores durante la primera época, sino “en su propio esfuerzo” (Ag. 1908: 323-35). El mecenazgo y el subsidio fueron entonces imprescindibles. Así lo documenta en sus memorias el director de la revista, Jesús F. Valenzuela (123-35). Este personaje prototípico de la cultura porfiriana dada su incursión ejemplar en la vida pública del régimen (confidente de poetas, de políticos y de millonarios; diputado y terrateniente [Quirarte 21]), no sólo fungió como el principal agente mediador entre el licencioso bar de los decadentistas y el foro de las buenas costumbres porfirianas, sino como promotor financiero al negociar el mecenazgo del millonario Jesús Luján y el subsidio de Ramón Corral, ministro de gobernación. A partir de 1904 la revista da cuenta de este tipo de financiamiento, con la reproducción del óleo de Ruelas, "La llegada de Luján a la RM" (Oct. 1907: 79), y con sucesivos tributos a Corral a través de fotografías y elogios (Dic. 1904: 240; Dic. 1905: 243; Ag. 1907: 363$64)$.

El hecho de ser producto de este patronazgo, no impide que en la revista se implante un sentido de cultura amplio y cosmopolita, siguiendo el ejemplo de revistas exitosas europeas como el Mercure de France (1890-1965). Entendido como necesidad de estar al día en materia literaria, este carácter cosmopolita se evidencia en la ojeada al mundo que la revista les proporciona a sus lectores a través de la intermediación francesa. ${ }^{10}$ Por otro lado, como paradójica homogeneización del modernismo en aras de la universalidad, el cosmopolitismo también se manifiesta en un relego del sectarismo decadentista, a partir de la muerte prematura de los fundadores decadentes (Couto, 1901 y Ruelas, 1907), o de su desaparición pública (Antenor Lescano, 1900), o de su paulatina subordinación a un consenso de gusto (Tablada, 1900), así como de la disposición estratégica de ciertos intelectuales que fungen como críticos mediadores. Tal es el caso de Miguel de Unamuno, quien brinda una visión mesurada del movimiento al enjuiciar el sectarismo en numerosos textos, en especial: “La Literatura Hispanoamericana” (15 Jun. 1903: 182-83). Una nota

\footnotetext{
${ }^{9}$ En 1895, sólo $14 \%$ de la población sabía leer. En 1910, 20 \% (González Navarro 532). A principios de siglo el 38 \% de la población era indígena y hablaba su propia lengua (Bazant, "Lecturas” 206). La circulación de los diarios se hacía por correo, dando una cobertura no mayor al $20 \%$ de los mexicanos (Toussaint 65-70).

${ }^{10}$ Ochenta y cuatro autores franceses de diversas corrientes publicaron numerosas colaboraciones durante la primera época. La intermediación francesa estuvo presente en la asimilación de D’Annunzio y Carducci (Jul. 1899: 206-08), y de Nietzsche en enero, abril, mayo y agosto de 1900, y junio de 1903. La revista introdujo, vía el Mercure de France, autores brasileños, catalanes, croatas y polacos. La presencia francesa disminuye en la segunda época.
} 
editorial acompaña este ensayo, arbitrando su lectura y confiriendo a Unamuno la necesaria autoridad para definir el modernismo como movimiento universal.

También es posible dar cuenta de un cosmopolitismo extraliterario y paradójicamente nacional, a través de la incidencia de escritores modernistas (Darío, Amado Nervo, Manuel Gutiérrez Nájera y Tablada) o de intelectuales positivistas (Gabino Barreda) en las políticas culturales del estado. Por ejemplo, Darío funge como vocero oficial del modernismo, pero también como un emisario de la modernidad hispanoamericana en el plano cultural y social al informar, desde la plataforma del Mercure de France en París (la revista reproduce sus artículos), sobre la intelectualidad extranjera (15 Ag. 1903: 245-48) o sobre los salones de la princesa Matilde (Ene. 1908: 315). El eco de Darío como corresponsal cultural reaparece en la revista constantemente, y se canaliza hacia las políticas de un estado modernizado, promotor y productor de cultura. Por ejemplo, la revista anuncia y reseña gráficamente la partida de sus ilustradores, también pintores nacionales, como Roberto Montenegro (Oct. 1905: 123), en viajes subvencionados de preparación vocacional a Europa; documenta las estancias diplomáticas de sus escritores, como Amado Nervo en Madrid (May. 1906: 192-93), y hace alarde de su alcance internacional a través de sus corresponsales: Urueta en Europa ([15 Ag. 1900]: 273-76; [1 Oct.]: 294-98; [15 Nov.]: 338-41) y Tablada en Japón. ${ }^{11}$

En las crónicas de Tablada, Japón aparece como el espacio compensatorio a la vulgarización del turismo, y el viajero, como el prototípico poeta modernista, amante de la belleza y desligado de cualquier propósito utilitario. No obstante, el hecho de que su viaje sea patrocinado por la propia revista como órgano autónomo de comunicación social, sugiere una política editorial: su presencia en el Japón daba a la RM la necesaria actualidad al convertirla en la primera publicación mexicana que mantenía una corresponsalía en un punto estratégico para el Occidente moderno; así lo anuncia la propia redacción el 15 de mayo de 1900 (154). Al lado de estos viajes de intención estética y preparación vocacional, la revista también documenta e ilustra otros trayectos menos literarios: desde las giras presidenciales y las campañas políticas (Dic. 1904: 221; Mar. 1906: 23) a través del territorio nacional, hasta los desplazamientos extraordinarios alrededor del globo terráqueo, de la gente “común”, como el emprendido “a pie y sin cuarto” por dos viajeros valencianos, “casi obreros”, llevado a cabo, no obstante, con el mapa que la lectura de las crónicas de viaje de Blasco Ibáñez, texto autorizado en la jerarquía de la ciudad letrada, les había proporcionado (Dic. 1907: 244-45). ${ }^{12}$

Con el fin de forjar el imaginario cosmopolita de sus diversos lectores, la revista ofrece un mapamundi del progreso que acoge a México en su seno. El centro era París, un referente ausente en realidad, puesto que encarnaba la novedad en sí misma. Fue precisamente la novedad el recurso que promociona la revista al reproducir, de publicaciones foráneas principalmente francesas, una variedad de textos e ilustraciones alusivos a

${ }^{11}$ (1 Jul. 1900): 200-203; (1 Sept. 1900): 257-61; (15 Sept. 1900): 282-83; (1 Oct. 1900): 290-93; (15 Oct. 1900): 312-15; (1 Nov. 1900): 333-36; (15 Nov. 1900): 342-44; (1 Dic. 1900): 257-59; (15 Dic. 1900): 370-73; (15 Ene. 1901): 27-29; (1 Feb. 1901): 45-48; (15 Mar. 1901): 90-91.

12 Blasco Ibáñez, el reseñista del viaje, sostiene: "Los dos muchachos me escribieron ... y adiviné ... que mis crónicas de viaje habían influido en la determinación de esta pareja de jóvenes” (244). 
nuevas formas de entretenimiento, como “El Kjoelke” (Ene. 1904: 323), o a la eficacia de una ciencia democratizada que se manifestaba en la vida cotidiana, como "Las maravillas del imán” (Oct. 1904): 92-94. Por otra parte, París también era una suerte de espejo mágico que mejoraba la fisonomía del país. Los viajes al interior del territorio nacional de Urueta (Oct. 1898: 65-68), Leduc (1899) ${ }^{13}$ y del Duque Job (1907) ${ }^{14}$ documentados por la revista, están escritos bajo el reflejo glamoroso de la ciudad luz. Este glamour se proyecta constantemente en las vistas de la capital, sinécdoque del país: en una afeminada vista panorámica (Tablada [15 Oct. 1898]: 94-95) y en un homenaje a la najeriana Calle de Plateros (Urueta, [1 Dic. 1898]: 129-30). Para los lectores de la revista, París y el interior de México se complementan: solamente hace falta darle vuelta a la página, para pasar de Montmartre al Paseo de la Reforma.

Las contribuciones de Nervo, su figura pública, y la promoción esgrimida a su favor mediante diversas reseñas y homenajes, contribuye a fortalecer este imaginario cosmopolita ligado al contexto nacional. ${ }^{15}$ Es Nervo quien en 1902 propone una conciliación entre el escritor y las políticas culturales del Porfiriato al elogiar la figura de Ignacio Manuel Altamirano, el intelectual más identificado con un concepto de literatura nacional, y promover el concurso de los Juegos Florales, para incrementar la poesía cívica (15 Jun. 1902: 164). A partir de 1907, Nervo se asocia a su vez a Gutiérrez Nájera, el fundador de la Revista Azul (1894-96) y el escritor más vinculado con la sociabilidad porfiriana, dado el elocuente registro citadino de su prosa, pero también a causa de la canonización de su figura pública como padre y esposo ejemplar, buen católico y ciudadano modelo; dicha edificación había sido documentada en la mencionada Revista Azul. ${ }^{16}$ Las contribuciones de estos escritores se publican alternadamente. Un homenaje dedicado a ambos es reproducido de El Liberal de Madrid en enero de 1909.

Como figura ejemplar, Gutiérrez Nájera fue también vehículo de concertación entre formaciones literarias. Cuando desaparece la efímera Savia Moderna (1906), publicación vinculada al Ateneo de la Juventud, la RM se convirte en el puente entre los residuales modernistas y los emergentes ateneístas; la defensa al legado de la Revista Azul y su fundador, a raíz de la aparición de una versión apócrifa de ésta, es el móvil inicial de tal concertación. ${ }^{17}$ Es entonces cuando la $R M$ auspicia una encuesta y una colecta para erigir una estatua a Gutiérrez Nájera en varios números de 1907. El empalme generacional se evidencia asimismo en los tipos discursivos que la revista publica. A partir de 1906 predominan la conferencia y el discurso. No sólo se publican las organizadas por Jesús Acevedo, de Pedro Henríquez Ureña sobre José María Gabriel y Galán (Jun. 1907: 296303), de Max Henríquez Ureña sobre el Duque Job (May. 1907: 139-41) y de Antonio Caso sobre Nietzsche (Ag. 1907: 349-58), sino también los discursos necrológicos a la memoria de Ruelas (Oct. 1907), al presidente de la Reforma, Benito Juárez (Mar. 1906 y 15 Jul. 1901), y al reformador positivista de la educación, Barreda (Mar. y Abr. 1908);

${ }^{13}$ (Ene.): 26-27; (Feb.): 59-60; (Mar.): 93-95; (May.): 158-60; (Jun.): 178-80.

14 (Abr.): 67-71; (May.):143-47; (Jun.): 195-200; (Jul.): 259-61.

${ }^{15}$ En el quinto y sexto años, la revista publicó El éxodo y las flores del camino, y veintiún notas bibliográficas sobre diversas obras. A partir de 1904, publica más de 67 contribuciones.

${ }^{16}$ Consultar Pineda sobre la canonización de Gutiérrez Nájera en la Revista Azul.

${ }^{17}$ Para una sinopsis de la concertación entre modernistas y ateneístas, consultar Curiel, 52. 
estas conferencias son articuladas por intelectuales reconocidos por su calidad oratoria, como Urueta (Mar. 1908: 3-7), pero también por hombres de la política y la economía, como Santiago Creel (Dic. 1905: 224-37). La calidad oratoria de este género es un rasgo del intelectual que ahora relega el refugio interior del modernismo e ingresa a la arena pública con una misión cultural a través del aula y el podio. La paulatina presencia de los ateneístas en el foro modernista se hace visible además con un uso discursivo de la fotografía. La serie “Rincones coloniales de México” hace de la arquitectura un patrimonio cultural, y de la Colonia, materia de renovado interés para el intelectual ateneísta. La fotografía también complementa la predilección por el temperamento clásico, ese que Pedro Henríquez Ureña apreciaba en el poeta castellano Gabriel y Galán (Jun. 1907: 303), mediante vistas crepusculares de los sitios arqueológicos grecolatinos (278).

El recurso fotográfico en la $R M$ también sistematiza el uso del paisaje nacional, sobre todo a partir de 1904, año de la reelección de Díaz, cuando se introduce la serie "Nuestros panoramas”. La nostalgia incitada en estas fotografías está acompañada por la creencia positivista de que ciertas prácticas y caracteres regionales están en peligro de extinción por su incapacidad para evolucionar y adaptarse (Rama 62). Así, una misma plaza pública (Ag. 1904: 83) se exhibe en dos tiempos: la de 1904 aparece cruzada por cables de electricidad; al lado de ésta se publica, a manera de contraste, la que rememora la época del Imperio con una sobria arquitectura colonial. En una crónica publicada en enero de ese mismo año, Darío apuesta por una fotografía que sea capaz de evocar épocas remotas con el encanto del arte pero que a la vez documente el pasado con la precisión del historiador moderno (298). Un uso de la fotografía que "reviviese la vida antigua americana" en el espacio de la celebración nacional (Darío 300-301) complementa la visión histórica en la revista. Se promueve un concepto de la historia parecido al articulado en la serie de ensayos The Spirit of the Age (1831) de Stuart Mill como record ordenado sobre el progresivo desarrollo de la sociedad (Bowler 6). El efecto de esta visión triunfalista descansa en el horizonte de un pasado fundacional para el presente porfiriano. Dicho horizonte es escenificado con los pactos establecidos entre sucesos mundiales de última hora, como la guerra entre España y Estados Unidos, provenientes de la sección “Notas de actualidad,” y el recuerdo nostálgico de figuras heroicas mexicanas, como “los niños héroes” (1 Sept. 1898: 47-48), ligadas principalmente a los triunfos del liberalismo. La Historia y la Literatura sirven en este sentido como telón de fondo de un nacionalismo cosmopolita y como amortiguadores de cualquier estremecimiento social. Las páginas conmemorativas al presidente Juárez son representativas: "La idea en actividad atraviesa la historia en una serie de encarnaciones diversas: Hidalgo con el tiempo se llamará Juárez” (Urueta, 13 [1901]: 218-19, reeditado en marzo de1906 [14-22]). Al lado de fotografías y diversos textos relativos al juarizmo, aparecieron otros alusivos a las giras y celebraciones presidenciales por el interior del país (Veracruz y Yucatán [1 Mar. 1906]: 2-35), con el fin de reconciliar las figuras de Juárez, “padre del liberalismo,” y de Díaz, supuesto hacedor de paz.

Acompañada de la plástica vanguardista de sus llamativas ilustraciones y de sus pórticos del arte europeo exhibidos en innumerables portadas, la revista propone un paisaje universal para la cultura y un mapa del país que oculte los vacíos del pasado a través del positivismo, no sólo en la visión de la historia, sino en ensayos laudatorios sobre Comte y Taine (Porfirio Parra [Oct. 1898: 70-71; 90-93] y Urueta [Ag. 1899: 233-34]). A partir 
de 1904 y, sobre todo en la segunda época, el positivismo se manifesta como pragmatismo social; el compromiso político se hace evidente con la proliferación de informes sobre reformas educativas, monetarias, municipales y de infraestructura. Pero es sobre todo en el ámbito de la educación formal, donde la revista manifesta su participación en la institucionalización del positivismo mediante la canonización de Barreda. Éste, junto con los liberales de la Reforma, había participado en un proceso de secularización a través de nuevos mecanismos de disciplina basados en el método científico, el nuevo eje integrador de lo social. A Barreda se le adjudica la implantación de un sistema educativo positivista a través de la reforma de instituciones públicas, principalmente la del antiguo Colegio de San Idelfonso, convertido en la Escuela Nacional Preparatoria con un currículo centrado en el estudio sistemático de las ciencias (Hale 385).

La presencia de Barreda en la $R M$ es temprana y recurrente: en marzo de 1899 se publican un panegírico de Urueta (71-74) y un discurso de Macedo (67-71), los cuales reaparecen en marzo de 1908 (3-7; 17-25). En 1901 la revista reimprime, en cuatro números consecutivos ([1 Ag.]: 237-41; [1 Sept.]: 276-80; [15 Sept.]: 292-95; [1 Oct.]: 311-12), el programa para la instrucción primaria que Barreda había formulado en 1875 con el fin de formalizar, en prácticas concretas, la idoneidad del positivismo en el ámbito de la educación. El programa establecía la necesidad de crear ciudadanos que satisfacieran la necesidad pública a través de la educación laica, y abogaba por el método científico, con su lógica inductiva y empírica, para clausurar las bases ontológicas en que se sustentaba la enseñanza, ya fuera en términos ilustrados o católicos. La proyección del plan de Barreda hacia una educación utilitaria y pragmática que posibilitara la explotación de recursos naturales con escuelas de enseñanza técnica, fue tarea del Porfiriato, y se manifiesta en la revista con la publicación de programas y reseñas de este tipo de instrucción; tal es el caso de "La universidad libre en perspectiva, grandioso proyecto del señor Enrique Creel”, reseña de Porfirio Parra publicada en enero de 1904, sobre la iniciativa de Creel de crear escuelas superiores de comercio, agricultura, minería, y artes y oficios (332-36), y de su respectivo programa, aparecido en marzo del mismo año (48085).

En 1908 se evidencia la explícita canonización del educador con la publicación de: “De la educación moral” texto del mismo Barreda ([Mar.]: 55-61) aparecido por primera vez en 1863, y de un conjunto de discursos y semblanzas en su honor, por Parra ([Mar.]: 32-36), Alfonso Cravioto (53-54), Sierra ([Abr.]: 67-76) y los mencionados, Macedo y Urueta. Mediante varios enfoques, desde el recuento personal sobre una accidentada formación intelectual previa a la emancipación inaugurada por el propio Barreda (Macedo, Mar. 1908: 19-23), hasta la inclusión del protagonista en la galería de héroes nacionales como reedificador del porvenir (Parra 34), estos textos asocian la libertad, presupuesto del progreso, con una educación anclada en el "orden” del método científico (35). Sin embargo, la reiteración del padre de la educación positivista en la $R M$ no responde únicamente a la intención de celebrar el positivismo como ideología de estado en un momento en que esta filosofía empezaba a perder crédito dentro de la misma revista en la pluma de los emergentes atenístas. Para precisar el propósito de esta tardía reiteración cabe resaltar el ensayo de Sierra. Éste cuestiona, desde los umbrales de la radioactividad a la que alude, la universalidad de la ciencia empírica como principio inmutable y como factor 
de cohesión social, subrayando la anacrónica base ideológica de Barreda en "De la educación moral” y poniendo de manifiesto la brecha entre 1863 y 1908; no obstante, también sugiere que la literatura, vista como práctica pedagógica vinculada a la emergencia del Castellano como disciplina escolar, contribuye a la (re)producción de subjetividades nacionales propias de un estado modernizado:

Lo que se le debe a Barreda es haber revolucionado la enseñanza del castellano apuntalando hacia la lectura y no hacia las reglas gramaticales. Y yo os aseguro que mi generación y las anteriores de que puedo hablar, supieron gramática, pero no supieron castellano ... y todo aquel que se atreva a ser franco, os dirá que ha conocido más la riqueza estupenda de nuestra habla, leyendo los libros actuales de los Galdós, los Valera, los Menéndez, los Pereda, que meditando todas las gramáticas de la Academia. (72)

La importancia del castellano a través de la práctica pedagógica en el seno de la modernización del estado se reitera en la $R M$ desde 1904, cuando, en el número cinco, se reedita el programa para la clase de Literatura que en 1894, ante el consejo superior de instrucción pública, había presentado uno de los fundadores de la revista, Balbino Dávalos (703-11). Este programa puede explicarse bajo el planteamiento de Juan Poblete, quien ha destacado, para el caso chileno, la relación entre la implantación del Castellano como disciplina escolar que sustituye al Latín, y la consolidación de un estado secular que hace de éste la lengua de su racionalidad. En forma de dictamen, el programa parte de dos posiciones, la sustentada por Diego Baz y José María Vigil, quienes proponen un conjunto de reglas para producir literatura, y la de Urueta y Nervo, quienes basan la enseñanza de la Literatura en el desarrollo de aptitudes. Dávalos dictamina el programa a favor de Urueta y Nervo, rechazando la preceptiva, la retórica y la metafísica y adoptando, como base de la enseñanza, la lectura directa de las obras. Los cambios que proponía el programa estaban encaminados a cancelar la práctica deductiva, basada en el uso paradigmático de los modelos clásicos para la explicación del presente. Asimismo, se implementaba una cronología de obras favorable a la articulación de subjetividades que leyeran por gusto, a través de una relación directa con la lengua y la Literatura: la prosa antes que la poesía, los géneros cortos (cuento y anécdotas) antes que los largos o complejos (novela y drama), los autores modernos antes que los clásicos. El plan asignaba al profesor la tarea de inducir el análisis a partir de la lectura del alumno y así internalizar el objetivo disciplinario de su educación. Una consideración importante es la que Dávalos articula en torno a la relación entre lengua y Literatura: "No creo posible formar un programa, no sólo definitivo, pero ni siquiera durable para la literatura, mientras no estén bien organizados los correspondientes a las lenguas vivas, especialmente los de la lengua materna” (709). Con la reedición de este programa, la $R M$ valida y reitera la incorporación del Castellano como práctica pedagógica en la clase de Lengua y Literatura, hecho consolidado en 1890, cuando esta materia se convirtió en la más importante del currículo escolar (Bazant, Historia de la educación 53). En sus informes, el educador Rébsamen declara que entre 1890 y 1900 se habían publicado más libros de lectura que en los tres siglos anteriores (54). El dato es útil para constatar que la revista contribuye a la institucionalización social de los textos literarios dentro de un sistema educativo modernizado y especializado. Lo literario se redefinía bajo un nuevo 
horizonte cultural que posibilitaba la “libre expresión” del ciudadano a la vez que inscribía una nueva forma de control.

Las reformas educativas que, además de la reestructuración del currículo, proponían la creación de escuelas normales y el incremento de libros de texto y bibliotecas (“Lecturas” 229-34), no sólo propiciaron nuevas formas de lectura, sino que contribuyeron, junto con otros medios como el periódico, a su diversificación. La RM, como órgano de difusión, reproducción e institucionalización cultural, detecta y a la vez encauza esta diversificación por vía del cosmopolitismo, apropiándose de modelos selectos, reproduciendo encuestas sobre la construcción de monumentos públicos (Duque Job), documentando concursos (como el de fotografía en mayo de 1904), auspiciando certámenes (los aludidos Juegos Florales) y renovando constantemente su carácter material. En 1903 facilita su manipulación física con un formato más pequeño (de 30 x $21 \mathrm{~cm}$. se reduce a 24.5 X 16.5), se hace más inclusiva, con una periodicidad mensual, y expande el número de sus páginas a treinta y dos; también cambia de nombre: Revista Moderna de México. Magazine mensual, político, científico, literario y de actualidad. Una nota de la redacción aclara el sentido del cambio al subrayar la incorporación de "variadísimas secciones científicas, literarias, artísticas, sociales, informativas” ([Ag.]: 256). A diferencia de las formaciones exclusivamente literarias, los magazines constituían foros públicos, en los que se incluían una serie de discursos extraliterarios, como aquellos que mediaban la recepción de algún autor o los que documentaban la correspondencia de los lectores para la discusión de diversos asuntos (Morrison 11).

Es evidente que el foro público inaugurado por la revista con estos cambios no estaba (pre)dispuesto únicamente para los receptores modelo (estetas finiseculares u "hombres cultos” del Porfiriato), también lo estaba para un sector femenino que se incorporaba paulatinamente a la vida ciudadana participando de los cambios acarreados por la modernización. Parte de este sector eran "las señoritas” que veinte años atrás habían irrumpido en la cátedra del sorprendido y receloso Gabino Barreda, aguardando "atentísimas las palabras del maestro” sobre “los fenómenos de la generación en la mujer” (Valenzuela, $R M$ [Dic. 1898]: 142-43). En la $R M$, las publicaciones alusivas a la incorporación femenina al espacio público (Antonina Coullet, May. 1903: 159; Olivia Schreiner, Jul. 1908: 2; Luisa Michel May. 1904: 23; Tina di Lorenzo, Ene. 1908: 6; Cándida Suárez, Jun. 1908: 14, y la mariscala Oyama del Japón, Nov. 1905) se manifiestan enmarcadas bajo un criterio de excepcionalidad y casi nunca dentro del contexto mexicano. No obstante, mediante la representación de los actos de lectura femeninos, en unas condiciones de espacio y tiempo ligados a la intimidad y al recogimiento, y por medio de ciertos formatos y géneros predilectos (la carta y el poema por sobre el ensayo y la crónica), la revista contribuye a la normatividad de la "libre expresión" de las mujeres. ${ }^{18}$ Como ejemplo de la configuración de la recepción femenina, retomemos las crónicas de Tablada sobre Japón; en éstas el narrador se representa como corresponsal que cumple las expectativas del “director” de la revista, pero también como sensible redactor de cartas dirigidas a una amada ficcional que lo espera en México en la intimidad de la casa. El cronista construye

${ }^{18}$ José María Martínez destaca estos géneros y condiciones en la configuración de la recepción femenina en la obra de Gutiérrez Nájera (15-29). 
un discurso escindido en dos espacios de representación de acuerdo al interlocutor interpelado: para la amada, éste configura un interior que acoge una visión lírica de recogimiento femenino, para el director de la revista, la escritura profesionalizada del corresponsal informa y reconstruye el espacio de lo público. Tablada mismo hace referencia a esta doble configuración desde su primera escala en San Francisco: "no creo oportuno ... hacer vibrar en estos artículos una perpetua crisis de íntimo lirismo. Vamos pues al grano: ¿quieres, querido Director, una serie de snap shots sobre esta ciudad de Yankilandia?” (1 Jul. 1900: 201). En 1901 la revista organiza un festival en memoria de Gutiérrez Nájera. La reseña de este acontecimiento ([15 Feb.]: 62-63) establece un paralelismo entre el prototipo de la lectora-personaje que Tablada representaba en su carta-crónica y las lectoras históricas que asistieron al evento. La reseña no solo reproduce la velada, sino que, a través de la mimesis, modela la recepción femenina de la siguiente manera:

Y aquellas damas, aquellas mujeres hermosas que lloraban o sonreían cuando Urbina leyó la soberbia prosa del llorado maestro ... o que perdían su mirada soñadora y húmeda en las blancas nébulas del tul que Chucho Contreras prendió a través de su elegante, soberbia y simbólica decoración. (63)

Es curioso que esta cita también subraye la percepción visual de las lectoras, al hacer referencia a la “decoración” hecha por el escultor finisecular Jesús F. Contreras, otro miembro allegado de la revista. Y es que la $R M$ también predispone a sus lectores y lectoras a través del registro visual. Por un lado, brinda variadas imágenes de un interior lírico, por el otro, suministra un consumo visual de lo público, aludiendo a una división del espacio relacionada por Walter Benjamin con la escisión síquica que experimentaba el ciudadano decimonónico: "the private citizen who in office took reality into account, required of the interior that it should support in his illusions” (167). Una metáfora de esta división es la sala de redacción de la novedosa revista, una fortaleza interior para los sujetos letrados en conexión con su "íntimo lirismo" y un enclave de apariencias para el gusto burgués, con sus tapices chinos, con sus “faunos bien esculpidos” y con "los cortinajes” que le daban "un aspecto señorial” (Campos, El bar 113).

Si la fotografía panorámica hace del territorio mexicano un sinónimo de la naciónestado gobernada por Díaz, el retrato fotográfico es central para la representación de estos dos espacios, especialmente a partir de 1903. Las fotos del hombre público (el gobernador de Zacatecas [Jun. 1908: 306] y el de Guerrero [Ag. 1907: 381], el vicepresidente Ramón Corral [Dic. 1904: 240; Ag. 1907:364] y el mismo Porfirio Díaz repetidas veces) y el cuerpo femenino de las señoritas “decentes” reproducen la moralidad porfiriana mediante una serie de tipologías que la lente captaba a través de la pose y la iluminación. Los retratos femeninos, reproducidos con mucha frecuencia a raíz del primer concurso de fotografía (mayo de 1904), evocan una economía doméstica y reivindican el necesario espacio privado, sostén de la esfera pública y de sus masculinos retos. La caracterización que hace Ruelas de la esposa de Valenzuela a raíz de su muerte, es representativa. El dibujante usurpa la sutileza prerrafaelita para representar un sujeto femenino ejemplar y localizable en el seno del Porfiriato (Ag. 1899: 256). La nota necrológica de la redacción complementa 
el mensaje visual: "La miramos hilando en una rueca de marfil, las horas de la vida, del hogar, fluidos y albeantes copos de lino que blandamente se deshacían en sus manos” (226).

Al lado de estas representaciones tendientes a disciplinar y modelar los hábitos de la burguesía porfiriana, se evidencia un registro espectacular, típico de la modernidad y dirigido a un observador susceptible a la ilusión óptica (Lalvani 176), proveniente principalmente de las ilustraciones de Ruelas y Montenegro. Animadas por el tropo romántico de la fantasmagoría, esa visión espectral del mundo detectada por Benjamin en el París de Baudelaire, las ilustraciones de Ruelas presentan una ambientación macabra, elementos fantásticos o fisonomías recrudecidas. Remiten a la tipología de la Nueva Mujer mediante poses y expresiones afines a las de pintores como Franz von Stuck y Félicien Rops. ${ }^{19}$ El friso rueliano más reproducido a manera de portada a partir del sexto año, es del cuerpo desnudo y yerto de una mujer estrangulada por una serpiente, evocativa de las Evas y las Lamias del arte finisecular. A pesar de que, a partir de su viaje a Europa en 1904, y después de su muerte en 1907, la presencia de Ruelas disminuye en la revista, y se hacen presentes otros ilustradores (el aludido Montenegro, Leandro Izaguirre, Germán Gedovius, Alberto Fuster, Ángel Zárraga y Diego Rivera), su sello permanece. Es factible suponer que las imágenes decadentes del pintor zacatecano se prolongan hasta el último número de la revista, caracterizándola como a ninguna otra de la época, porque el desplazamiento metafórico de su composición asegura una lectura visual en el plano de lo fictivo. ${ }^{20}$ Es por ello que la muerte de sus alucinadas mujeres, los torturados rostros de sus personajes decadentes, e incluso la apropiación nostálgica de su propia muerte prematura en notas necrológicas de 1907, son admisibles en una revista, que, en la página consecutiva, celebraba la vida eterna del Porfiriato con una fotografía alusiva al orden y al progreso. La subordinación del estilo modernista a la promoción de los artículos de lujo que el mismo Ruelas ilustraba y que la revista promocionaba, es una prueba más de esta complicidad, sobre todo si se tiene en cuenta que gran parte de estos anuncios eran leídos por las señoritas del Porfiriato. ${ }^{21}$

Para recapitular, desde la versión de los fundadores, la $R M$ emerge como un espacio cultural antagónico a la moral pública del Porfiriato mediante la asimilación de tópicos y procedimientos provenientes del decadentismo europeo. No obstante, ésta no sólo contribuye a la propagación de las letras finiseculares europeas e hispanoamericanas, sino también a la institucionalización social de la Literatura como práctica pedagógica, así como a la reproducción de un esfera pública sustentada en costumbres y hábitos encaminados a fortalecer los mitos del régimen: la armonía cívica, la utopía de un pensamiento científico único, la posicionalidad de Francia como la meca universal de la

${ }^{19}$ La $R M$ publicó una serie de reproducciones del pintor alemán, pertenecientes a la colección de Luján en noviembre de 1906 (163-67). La afinidad con Rops es evidente, como hace notar Del Conde al comparar "Pornokrates" de Rops con La "domadora” de Ruelas (ill. 22-23).

${ }^{20}$ Este es el argumento de Elizabeth Bronfen sobre la poética de Edgar Allan Poe: "because it is a poetical topic, Poe's fantasy of femenine death remains innocent of real violence" (71-72).

${ }^{21}$ Sobre el compromiso político y estético del dibujante y su conversión en asalariado, consultar Bartra, quien sitúa la obra de Ruelas no sólo en la RM sino también en El Cómico (95). Sobre la predisposición de los anuncios publicitarios para la lectura femenina, consultar, Zamora (53). 
cultura moderna, la geografía urbanizada de un país que se insertaba en la modernidad sin perder su vocación sentimental, y el espejismo de ser partícipe de una sociedad que permitía la apertura hacia nuevas formas de expresión cultural y social. Una serie de marcadores materiales (convenciones adoptadas de otras publicaciones exitosas, su elocuente formato, su papel satinado, su gráfica y la incorporación de la fotografía como recurso comercial, político y artístico) contribuyeron a formar el horizonte de expectativas lectoras. En sus páginas glamorosas, decadentes, regionales, femeninas, políticas, comerciales, los porfirianos y las porfirianas imaginaron el futuro de la nación como en una vitrina que ostentaba una diversidad de vistas, pero siempre con Don Porfirio a la cabeza. A pesar de la creciente urbanización que se llevó a cabo a lo largo de setenta años, la irrupción de una revolución campesina, la de 1910, concluyó con el Porfiriato de manera violenta. Como el régimen, la revista desapareció en junio de 1911, un mes después de la muerte de su fundador Valenzuela, ante la conmoción revolucionaria que desmanteló la ilusoria plataforma cosmopolita que la sostuvo.

\section{BiBLIOGRAFÍA}

Bazant, Mílada. Historia de la educación durante el Porfiriato. México: El Colegio de México, 1993.

"Lecturas del Porfiriato". Historia de la lectura en México. Pilar Gonzalbo, ed. México: El Colegio de México-Ediciones El Ermitaño, 1988. 204-39.

Bartra, Armando. "El periodismo gráfico en las dos primeras décadas del siglo: de la subversión a la restauración con intermedio escapista”. Las publicaciones periódicas y la historia de México. (Ciclo de conferencias). Aurora Cando Andaluz, ed. México: Universidad Nacional, 1995. 89-103.

Benjamin, Walter. Charles Baudelaire: A Lyric Poet in the Era of High Capitalism. Trad. al inglés. Harry Zohn. Londres: Suhrkamp Verlag, 1973.

Bowler, Peter J. The Invention of Progress. The Victorians and the Past. Oxford: Basil and Blackwell, 1989.

Bronfen Elizabeth. Over her Death Body. Death, Feminity and the Aesthetic. New York: Routledge, 1992.

Campos, Rubén M. El bar. La vida literaria en México en 1900. México: Universidad Nacional Autónoma de México, 1996.

Cando Andaluz, Aurora, ed. Las publicaciones periódicas y la historia de México. (Ciclo de conferencias). México: Universidad Nacional, 1995.

Curiel, Fernando. “El ateneo modernista”. Literatura Mexicana 7/1 (1996): 39-59.

Del Conde, Teresa. Julio Ruelas. México: Universidad Nacional Autónoma de México, 1976.

Gonzalbo, Pilar, ed. Historia de la lectura en México. México: El Colegio de MéxicoEdiciones El Ermitaño, 1988.

González Navarro, Moisés. El Porfiriato. La vida social. México: Hermes, 1970. 
Hale, Charles A. "Political and Social Ideas in Latin America, 1870-1930”. The Cambridge History of Latin America. Leslie Bethell, ed. Vol. 4. Cambridge: Cambridge University Press, 1986. 367-441.

Holdsworth, Carole. A study of the Revista Moderna. Mexico, 1898-1903. Diss. Northwestern University. 1965.

Lalvani Suren. Photography, Vision, and the Production of Modern Bodies. Albany: State University of Nueva York Press, 1996.

Martínez José María. "El público femenino del modernismo: de la lectora figurada a la lectora histórica en las prosas de Gutiérrez Nájera”. Revista Iberoamericana 57/194195 (enero-junio 2001): 15-29.

Morrison Mark, S. The Public Face of Modernism. Little Magazines, Audiences, and Reception 1905-1920. Madison: University of Wisconsin Press, 2001.

Pineda Franco, Adela. "El afrancesamiento modernista de la Revista Azul (1894-96): ¿un arte decadente o una apología del progreso positivista?” México-Francia. Memorias de una sensibilidad común. Javier Pérez Siller, ed. México: BUAP, 1999. 395-420.

Poblete, Juan. "El Castellano: la nueva disciplina y el texto nacional en el fin de siglo chileno”. Revista de Crítica Cultural 15 (Nov. 1997).

Quirarte Vicente, ed. Prólogo. Mis Recuerdos. Manojo de Rimas. Jesús E. Valenzuela, ed. México: Consejo Nacional para la Cultura y las Artes, 2001. 13-40.

Rama, Ángel. La ciudad letrada. Hanover, NH: Ediciones del Norte, 1984.

Revista Moderna. Arte y Ciencia. Dir. Jesús E. Valenzuela. (Jul. 1898-Ag.1903). 6 Vols. Edición facsimilar. Revista Moderna. Arte y Ciencia. México: Universidad Nacional Autónoma de México, 1987.

Revista Moderna de México. Magazine mensual. Político, científico, literario y de actualidades. Directores propietarios Jesús E. Valenzuela y Amado Nervo. México, Sept. 1903-Jun. 1911.

Rodríguez Lobato, Marisela. Julio Ruelas...siempre vestido de huraña melancolía: temática y comentario de la obra ilustrativa de Julio Ruelas en la Revista Moderna, 1898-1911. México: Universidad Iberoamericana, 1998.

Schneider, Luis Mario. Ruptura y Continuidad. La literatura mexicana en polémica. [1975]. México: Fondo de Cultura Económica, 1986.

Speckman Elisa. "La prensa, los periodistas y los lectores (Ciudad de México, 19031911)”. Revista Moderna de México (1903-1911) II. Contexto. Belem Clark de Lara y Fernando Curiel Defossée, eds. México: Universidad Nacional Autónoma de México, 2002.

Torri, Julio. Prólogo. Edición facsimilar. Revista Moderna. Arte y Ciencia. IX-XIV.

Toussaint Alcaraz Florence. Escenario de la prensa en el Porfiriato. México: Fundación Manuel Buendía, 1984.

Valenzuela Jesús E. Mis Recuerdos. Manojo de Rimas. Vicente Quirarte, ed. México: Consejo Nacional para la Cultura y las Artes, 2001.

Valdés Héctor. "Estudio introductorio". Edición facsimilar. Revista Moderna. Arte y Ciencia. XV-XXXVIII.

Índice de la Revista Moderna Arte y Ciencia. (1898-1903). México: Universidad Nacional Autónoma de México, 1967. 
Zamora Casillas, Yolanda. “Alacena publicitaria”. Revista Mexicana de Ciencias Políticas y Sociales 28/109 (1982): 47-54. 